\title{
Development of a Neuroscience Motifs-based Teacher Training Program for Pre-Service Teachers in Special Education in Israel
}

Efrat Luzzatto, Alina. S. Rusu 


\title{
Development of a Neuroscience Motifs-based Teacher Training Program for Pre-Service Teachers in Special Education in Israel
}

\author{
Efrat Luzzatto $^{a, b^{*}}$, Alina. S. Rusu ${ }^{c}$ \\ ${ }^{a}$ Department of Special Education, Levinsky College of Education, Tel-Aviv, Israel \\ ${ }^{b}$ Doctoral School Education, Reflection, Development, Babeș-Bolyai University, Cluj-Napoca, Romania \\ ${ }^{c}$ Department of Special Education, Babeș-Bolyai University, Cluj-Napoca, Romania \\ *Corresponding author: efratluz@gmail.com
}

\section{Abstract}

Keywords:

Curriculum Change;

Curriculum Planning; Pre-

Service Teachers;

Neuroeducation; Teacher

Training Program
In the last two decades, there is an increasing interest in the connection between neuroscience and education. However, there is a gap between the declarative statements about the importance of implementation of neuroscience in education and the small number of suggested programs which actually present an implementation in practice. This study describes the development, design and the planning of implementation of a Neuroscience Teacher Based Teacher Training Program (NMTTP) for Pre-Service Teachers (PSTs) in special education track. In addition, this study presents the current literature addressing neuroeducation and curriculum, describes the gap in knowledge concerning it and focuses on the need for constructing a neuroeducational curriculum, specifically when dealing with learning disabilities. The structure of the neuroscience-based training program, its main topics and its originality are presented and discussed.

\section{Zusammenfasung}

\section{Schlüsselworte:}

Lehrplanänderung;

Lehrplanentwicklung; Lehrer

in Ausbildung;

Neuropädagogik;

Lehrerausbildungsprogramm
In den letzten zwei Jahrzehnten ist ein zunehmendes Interesse an der Verbindung zwischen Neurowissenschaften und Bildung zu verzeichnen. Es besteht jedoch ein Missverhältnis zwischen der in der Literatur dargelegten Wichtigkeit der Umsetzung der Neurowissenschaften in der Bildung und der geringen Anzahl bestehender Programme, die tatsächlich als eine Umsetzung in die Praxis bezeichnet werden können. Diese Studie beschreibt die Entwicklung, das Design und die Einführungsplanung eines neurowissenschaftlichen Ausbildungsprogramms für angehende Lehrer der Sonderpädagogik. Darüber hinaus fasst diese Studie die gegenwärtige Literatur zur Neuropädagogik in Lehrplänen zusammen, weist auf bestehende Wissensdefizite hin und konzentriert sich dabei auf die Notwendigkeit, einen neuropädagogischen Lehrplan zu erstellen, insbesondere für die Ausbildung von Schülern mit Lernschwierigkeiten. Die Struktur des auf den Neurowissenschaften basierten Ausbildungsprogramms, seine Schwerpunkte und sein faktischer Nutzen werden vorgestellt und diskutiert.

\section{Introduction}

Neuroeducation (NE) is a growing interdisciplinary field, which is based on the synergic connection between neuroscience, cognitive science, psychology and education in an effort to improve the theoretical and practical understanding of learning and education (Devonshire \& Dommett, 2010; Nouri, 2013; Rodgers, 2015; TokuhamaEspinosa, 2018). Although NE has gained importance in the educational communities in the recent years, there is still not enough information on how it is implemented in the classroom (pedagogical practice, curricular content), especially in the context of teacher training (Murphy, 2017).

In terms of interest in NE in Israel, the level is increasing in the last few years (e.g. Achva Model of Neuropedagogy, 2016), but the assimilation and implementation of NE elements in teacher training colleges is still in its early stages. This study focuses on describing a teacher-training program and a suggested curriculum, which would allow the implementation of motifs from neuroscience in a reading class for pre-service teachers (PSTs) in the field of Special Education in Israel. Hence, the main objective of this research is to describe the development, design and the planning of implementation of a Neuroscience Teacher Based Teacher Training Program (NMTTP) for Special Education Pre-Service Teachers (PSTs).

This study follows the curriculum design principles for developing modules in education suggested by Remesh (2017). According to these principles, the curriculum design contains several components, such as: educational description, targeted need assessment, objectives, educational activities, assessment methods and evaluation. 
The study is divided into the following parts: 1. A general review of the literature addressing the curriculum and NE. 2. A detailed description of the research field and the intervention program design. 3. A section presenting the particular aspects of the neuroscience motif-based training program (NMTTP).

\section{Theoretical foundation}

\subsection{General Aspects of Curriculum Design}

Curriculum is considered the crux of an educational process (Remesh, 2017). According to Remesh (2017), curriculum is a blueprint, which is systematically planned and leads to changes in learners in four domains: cognitive (knowledge and intellectual skills), affective (feelings and attitudes), interpersonal (social behavior and relationships with others), and psychomotor (physical skills). Clement \& Lovat (2012) refer to curriculum work as a decision-making process that involves the selection of content and the crafting of pedagogies that are relevant to the targeted learners. The difference between curriculum and syllabus is that while the second one is a static element, the curriculum is a dynamic and moving one (Remesh, 2017). According to this, a curriculum design should be systematic, yet flexible, especially on the way to accommodate implications of varying educational contexts. A module is a subunit of curriculum, and the steps in curriculum development are applied also in developing modules (Remesh, 2017).

\subsection{Neuroeducational Curriculum}

In recent years, attempts have been made to implement neuroscience knowledge and research findings into pedagogy and classroom teaching for advancing teaching and learning (Friedman et al., 2019). According to Tokuhama-Espinosa (2017), the knowledge derived from neuroscientific research might offer new perspectives on understanding the mechanisms of teaching and learning. Curtis \& Fallin (2014) state that, in order to meet the challenges of teaching in today's educational settings, there is a need for a new breed of teachers who are interested in not only what they teach, but also how the brain learns. Ergaz et al. (2018) claimed that there is a growing agreement among educators that neuroscience can serve as an important turning point in initiating evidence - based pedagogical and educational practices, which in turn might serve to empower teachers' professional performance.

A clear review of concepts from the NE field can help educators identify neuromyths, which are common misconceptions that can influence program-related decisions made by schools or districts. As summarized by Tokuhama-Espinosa (2017), the 2016-2017 International Delphi Panel on Mind, Brain, and Education Science sought to document the advances the field has made over the past decade and to acknowledge the challenges that remain, which can serve to guide the agenda for development and research into the next decade. Within the different challenges presented in the committee, one of the main ones is the integration of NE into General Teacher Education. The other challenges refer to the integration into the education system and to the process of raising the general public understanding and use of NE concepts, thus convincing educators about the importance of understanding learning processes for improving educational outcomes. The challenges also included the understanding that most educators do not have the scientific grounding to be able to appreciate the significance of this implication and the need to help teachers use neuroscience ideas in the design of curriculum. In addition, it was recommended that more research should be conducted to determine specific course recommendations to teacher colleges in order to increase teachers' basic understanding of the human brain and learning processes, by providing a mental framework for teachers to understand distinct psychological factors that might influence the classroom practice (TokuhamaEspinosa, 2017).

Clement \& Lovat (2012) address the issue of neuroeducational curriculum and claim that this issue raises at least three interrelated questions for the curriculum work. The first is whether neuroscience is to be regarded among that corpus of disciplines that comprise the educational foundations. The second is whether, in fact, it is possible to "translate" neuroscientific knowledge to education in ways that preserve the epistemic interests of both disciplines and the third is whether usable knowledge can be generated from neuroscientific information that teachers can employ in their curriculum work. After discussing these questions, it was concluded that it belongs to the field of curriculum work where and whether neuroscientific knowledge must be translated into usable knowledge because it is here that teachers apply educational theory to practical problems. According to the authors, the translation of educational neuroscience into knowledge that teachers can use in curriculum work, depends a lot on the accessibility of the neuroscientific knowledge and the connections with practical issues.

Based on the literature discussed above, it seems consensual that brain research can help teachers enhance their educational and teaching capabilities. However, despite this assumption, only few studies address the implementation of NE in the classroom. Dubinsky et al. (2019) claimed that the problem is how to provide accurate neuroscience content to meet teachers' needs to evaluate educationally related claims. According to the authors, the role could easily be assumed by neuroscientists themselves 
offering courses to pre-service and in-service teachers, and pedagogy specialists can help teachers navigate the connections between the content and the techniques modeled during the workshops (Dubinsky et al., 2013). In line with this, Dubinsky et al. (2019) presented a project called "BrainU", which was created as a professional development program to provide teachers with an opportunity to learn neuroscience. BrainU was originally developed to provide $\mathrm{K}-12$ teachers with sufficient neuroscience content knowledge so that they could successfully teach their students about the neuroanatomy and the functionality of the brain. The curriculum was written for middle and high school classrooms covering knowledge about basic synaptic connectivity, sensory and motor functions, learning and memory, the autonomic nervous system, emotional processing, motivation and reward circuits, adolescent brain development, and diseases of the nervous system including addiction. Pedagogy specialists helped teachers navigate the connections between the content and the techniques modeled during the workshops. Teachers also read primary neuroscientific and educational literature to develop the capacity to critically analyze overinterpretations connecting the fields. Beyond their content, these lessons were modelled in the professional development workshops, incorporating activelearning and learner-centered strategies that included model making, observation, exploration, experimentation, data analysis, interpretation, and discussion. BrainU modeled assessing prior knowledge, constructing explanations, and identifying, discussing, and overlaying misconceptions with appropriate new concepts. Attention was paid to implementing equitable and culturally sensitive classroom practices. According to the authors, teachers completing BrainU workshops acquired neuroscience knowledge and were able to teach it successfully to their students. The results indicated that the neuroscience knowledge impacted teachers' view of learning and of their students' potential. Importantly, multiple sets of BrainU participants linked the idea of synaptic plasticity to the efficacy of learner-centered pedagogies that promote higher order thinking and profound learning in their students. From their experiences, teachers indicated that learning neuroscience was welcomed and had positive, perhaps transformational, impact on their professional practice (Dubinsky et al., 2019).

Friedman et al. (2019) were also interested in the implementation of neuroscience in education, and discussed three main open questions related to the implementation process: First, what are the neuroscience content areas or neuroscientific findings that are crucial to teaching and learning? Second, how to provide teachers with the relevant neuroscience concepts in a way that changes teaching practices and interactions with students? Third, how can neuroscience knowhow be translated into educational practice in practical terms? In order to answer those questions, the authors developed a three-year Neuropedagogy Adaptation Project (NAP) to expose practicing teachers to neuroscientific knowledge for productive classroom practices (Friedman et al., 2019). The teachers who participated in the program stated the importance that educators be equipped with basic knowledge in the field of neuroscience and familiarity with its structure and functions. According to the authors, NE can also improve teaching abilities by suggesting innovative teaching practices, enhances productive learning and improves teacher-student relationships (Friedman et al., 2019). This is especially pertinent when preparing novice teachers for their future role, and emphasizes the importance in integrating neuroscience in the teachertraining curriculum, as well as in professional development seminars for in- service teachers. Murphy (2017) agrees with this interpretation, by saying that teachers' practices should be informed by current neuroeducation research and theory. This knowledge will serve students well, and legitimize teaching as a profession.

In conclusion, it seems there is a gap between the declarative statements about the importance of implementation of neuroscience in education, and the small number of suggested programs, which actually present an implementation in practice. The existing programs presented above indicate that there are positive results and enthusiasm from the participants regarding the induction of neuroscience into their work. However, it also seems that there is still no specific curriculum to guide the implementation of NE in education.

\subsection{NE Curriculum Regarding Learning Disabilities}

The potential of NE in elucidating the core cognitive and neural deficits and the efficacy of training and intervention program seems apparent, since neuroscience can provide valuable knowledge about the brain abnormalities that accompany these deficits. The different levels of understanding of learning disabilities such as dyslexia, dyscalculia or ADHD might shed light on possible treatments and the best methods to teach the children who suffer from them (Gabrieli, 2016; Rueda 2020). According to Stern et al. (2016), it appears that for a better understanding of human learning in academic settings, constraints set by the architecture of the human brain have to be taken into consideration. Moreover, educators should be able to know how students, especially in special education, best require, retain and apply knowledge in creative ways, since conventional ways of teaching often do 
not attain the expected achievements among those with difficulties. The field of NE has much to offer in this regard (Hardiman, 2012a), since neuroscience may have profound implications for individuals with disabilities (Kosaraju et al., 2014). Nevertheless, reviewing the databases of articles addressing the combination of the keywords "NE" and "learning disabilities" does not yield a large amount of research. Most of the researches deal with the neurological explanations of different learning disabilities (LD), such as dyscalculia or dyslexia and the implications of those findings (e.g., Bravo, 2014; Katzir \& Pare-Blagoev, 2006; Kearns et al., 2019). Only few researches suggesting a curriculum regarding courses dealing with learning disabilities and NE can be currently found in the literature. Dresler et al. (2018) suggest a theoretical and empirical guide of the benefits of neuroimaging, which can help people who work with different aspects of LD. In their model, four components reflect the ways NE can inform learning disabilities. The first component is represented by the mechanisms, meaning the neural and cognitive substrates underlying a specific dysfunction. These mechanisms should be investigated based on multifactorial causal framework of learning disabilities. The second component is diagnosis/prognosis. The knowledge of the nature of the mechanisms involved in a specific learning is essential in contributing to the diagnosis and early detection of the disorder. Reliable diagnosis based on multifactorial causal framework of learning disabilities are likely to increase the reliability of individual's learning disabilities' prognosis and to predict accurately their developmental trajectory. The third component is intervention training. A better prognostic knowledge based on a theoretically grounded diagnosis can initiate neuroscientifically informed intervention training students with learning disabilities. The fourth component is community and education. According to the authors, the first three components lack a direct applicable educational relevance, and do not offer practical solutions. To do so, tranferring systematic knowledge into the community and education practice is necessary. Time should be invested in the effort to improve the connections and interactions between the different components and especially developing effective interventions (Dresler et al., 2018).

\subsection{Particularities of PSTs Training in Special Education in Israel}

Special Education studies in Israel seek to train educators in learning processes for children with special needs in all educational frameworks, such as segregated frameworks for ages $6-21$, such as: mental disabilities, multi-problem learning disabilities, communication disabilities, sensory disabilities, emotional and behavior disorders, as well as inclusive frameworks integrating children with special needs in the normative classes, in special education classes in normative schools and in other frameworks such as community and regional support centers (Hoffenbartal, 2014). Within this track, there are two areas of specialization in Israeli Special Education system: The Special Education Single Course of Study and the Dual-Major Course of Study: Special Education and another discipline. The PSTs in the Special Education Single Course of Study participate in practical work in special education classes once a week for five hours. The PSTs of the Dual-Major Route participate in practical work twice a week for five hours each time - one day in special education and the other in a mainstream class in a mainstream school. The curriculum design is based on two major principles/approaches: The first is a humanistic approach, which respects human diversity and regards it as a resource for advancing each individual in the educational domain. The second is the inclusive educational approach directed to the integration of children with special needs into mainstream school life. The program grounds knowledge in the areas of the characteristics of populations and disabilities in special education, unique treatment approaches for children with different levels of disabilities, integration and inclusion of children with special needs in mainstream frameworks, working with multi-disciplinary teams, relationships with the family and more. During the three years of studies, the PSTs acquire knowledge in the area of special education, while focusing on the characteristics of populations and disabilities in special education (mental disability, autism, learning disabilities and more); knowledge of the Special Education Law and the Inclusion Guidelines, and the nature of coping on academic, social and emotional levels. The courses reflect the complexity of teaching populations with special needs such as PDD, learning disabilities, hearing and sight impairments, emotional and behavioral disorders and more. In addition to the courses in the college, the PSTs practice teaching in different schools once or twice a week. Moreover, each semester they practice for a full week in the classes and experience the daily routines at school. In the second year of practice, the PSTs teach a special education class, usually with pupils with learning disabilities, in a teaching unit they decide on with the class teacher. In addition, they choose one pupil from the class, and they practice the diagnosis and reading intervention program they learned in the reading courses. Every year, the PSTs are required to take a mentoring course, which accompanies their practice teaching and enables them to acquire tools for developing programs for special needs populations, developing remedial teaching and assessment methods, 
becoming familiar with alternative communication methods and with unique curricula and technologies in special education (Hoffenbartal, 2014).

This study focuses on developing a NE-motifs based program (NMTTP) for PSTs during their second year of study in the Special Education track. During this year, the focus is on interaction between the PSTs and a group of pupils. Specifically, the PSTs practice teaching pupils with learning disabilities and their focus is on teaching a small group of pupils from the class, in addition to teaching the whole class. One of the mandatory courses in the special education track and in which the NMTTP was implemented, i.e. "Reading Disabilities - Theories and Intervention Programs", deals with teaching reading to pupils with special needs, especially those with learning disabilities. The course has several units, as they follow: the introduction unit, which deals with the definitions of reading and dyslexia and the spoken language components in relation to reading; the models unit, which presents several of the main models explaining the route to proper reading; the diagnosis unit which demonstrates mapping a diagnosis to identify students with reading difficulties; and the reading comprehension unit, which deals with a variety of causes of reading comprehension difficulties, and presents various strategies for dealing with them. The studies in this course combine frontal teaching together with more innovative teaching styles, and, throughout the course, different proposals for learning strategies are presented and suggested. Subsequent to the above is an online course named: "From Diagnosis to Developing Instructional Programs in Reading for Pupils with Reading Difficulties", which focuses is on one pupil chosen from the learning disabilities class of practice. The PSTs learn to write a pupil's profile, which comprises different aspects such as: academic, social, cognitive, family aspect, reading habits, attitudes toward reading etc. They practice the diagnosis studied in the reading course and they learn to create an intervention program focusing on the pupil's specific difficulties in reading while implementing it in their practice. Both courses are linked and discussed in the reading course.

In this study, the strategy of developing the structure of a neuroscience motif-based training program (NMTTP) was based on creating a module (Clement \& Lovat, 2012), by adding content and methods to an existing syllabus, implementing it in class and assessing it as reflected in students' interviews and lesson planning by the pre-service teachers.

\section{Research Methodology \\ 3.1 Program Design}

The topics chosen for the NMTTP were based on the guidelines of the Brain Targeted Teaching Model (BTT) by Hardiman (2012) and on the ideas of Tokuhama-Espinosa (2011) presented in the guide to brain-based teaching, as well as by several original lessons developed by the corresponding author (EL). Hardiman (2012) created a model based on six brain targets: (1) establishing the emotional climate for learning, (2) creating the physical learning environment, (3) designing the learning experience, (4) teaching for mastery of content, skills and concepts, (5) teaching for the extension and application of knowledge- creativity and innovation in education and (6) evaluating learning. Tokuhama-Espinosa (2011) referred to similar as well as additional topics in her guide, such as neuromyths, emotional state and motivation, attention, the academic fields related to NE such as language and math, and evidence based solutions for the classroom. The NMTTP was drew based on the principles mentioned above, but specifically connected the vast ideas of NE with reading. Moreover, innovative topics such as mirror neurons or spaced learning were implemented and added, as detailed below. The following nine topics were included in the structure of the NMTTP:

1) Learning in context refers to the connection between prior knowledge of the learner and the new information in the context, which can be used to perform the learning task. It is generally assumed that learning in context will increase performance in knowledge acquisition, recall and transfer (Norman, 2007, in Bergman et al., 2015). Hardiman (2012b) suggests that prior knowledge is used to categorize stimuli which are combined with new knowledge to create patterns of thinking and learning. In the NMTTP, and because of the importance of this concept, learning in context was a central concept which followed the entire program.

2) Neuroplasticity - refers to the nervous system's capacity to change as a result of influences from the external environment or internal environment states during an organism's development and life span (García Carrasco et al 2015). The concept was taught and mentioned several times during the NMTTP, in relation to adjusting teaching for pupils with learning disabilities and the different teaching methods which can fit the plasticity principle.

3) Neuromyths - Neuromyths are semi-scientific assumptions which were made as a consequence of overgeneralization about the human brain often being used to justify ineffective approaches to teaching. According to the OECD (2007), neuromyths are 'hypotheses which have been invalidated, nevertheless leave traces and if these have captured a wider imagination, "myths" take root' (OECD, 
2007, P. 108). According to Tokuhama-Espinosa (2011), neuromyths are typically produced due to a partial fact or a single study or in some cases outright misinterpretations of data. In the NMTTP, a special lesson was dedicated to this topic, which is one of the major justifications for the importance of evidence- based teaching and NE.

4) Brain and reading - Reading and dyslexia are major concepts in the reading course. Neuroimaging has led dyslexia research to a better understanding of the mechanisms involved in its different subtypes, providing measures that correlate with a myriad of behavioral data (Boets et al., 2013). Due to technological advancement, neuroimaging shows the effect of intervention programs in reading in pre-and post-training researches (Dresler et al., 2018; Partanen, 2017). Different researches relating to this were presented in class as part of the NMTTP lessons.

5) Metacognition and the brain - Metacognition is the process of considering and regulating one's own learning and thinking processes (Tokuhama-Espinosa, 2011; Young \& Fry, 2008). It refers to the ability of a person to rethink his thinking, steer his cognitive process in correspondence to his conclusions, and to monitor and control his cognitive processes (Goswami, 2008). The use of metacognitive strategies elicits different neural activation patterns than the use of strategies involving less cognitive effort (Moss et al., 2013).

6) Mirror neurons - Mirror neurons are neuronal cells that fire both when an individual performs an action and when the individual sees or hears another perform a similar action (Keysers et al., 2003). In the NMTTP, the mirror neurons were mentioned in the diagnosis unit, referring imitation to learning and empathy.

7) Working memory and the brain - Working memory is a complex cognitive system in which information is held in awareness so it can be manipulated (Baddeley, 1992). It helps us hold some information in our mind while doing other things. Working memory is an inseparable part of processes of retrieval and learning new information. In the NMTTP, a special lesson was dedicated to this topic, with relation to reading, attention and reading comprehension.

8) Physical activity and its importance to learning The typical classroom setting in which students "sit and get" was challenged by research findings showing that the brain is more active when learners are moving around (Sousa, 2010). It appears that movement allows the brain to access more long-term memory areas, thereby helping students make greater connections between new and prior knowledge (Sousa, 2010). During the NMTTP, the students study and practice physical activity in learning (e.g lesson no. 8 , the working memory lesson) and were encouraged to get their pupils to move around in the classroom.

9) Spaced learning - The concept refers to learning in chunks, with breaks between those chunks. Research has found the neurological mechanism that explains why this spacing effect is important for the consolidation of memory (Hardiman, 2012). Spaced learning is a learning method in which highly condensed learning content is repeated three times, with two 10-minute breaks during which distractor activities, such as physical activities, are performed by the pupils. Several studies indicate that spaced learning helps consolidation of information in memory and contributes to academic success (Ram-Tsur \& Litmanovitch, 2018; Smolen et al., 2016). In the NMTTP, the spaced learning is presented and practiced in class, with critical thinking about its implications to teaching.

\section{Results}

4.1 Proposed procedure for the implementation of the NE-based program

The NMTTP spread over one academic year (two semesters). It comprised 10 major lessons (each lesson had a total duration of 90 minutes, including the reading lesson content) during the academic year, which are presented in brief in Table 1 .

Table 1. An overview of the NMTTP lessons.

\begin{tabular}{|c|c|c|c|c|}
\hline Lesson & Purpose & Key concepts & Teaching methods & $\begin{array}{l}\text { Materials needed or } \\
\text { other variables }\end{array}$ \\
\hline 1 & $\begin{array}{l}\text { Presenting the purpose of the } \\
\text { study }\end{array}$ & Neuroeducation & Discussion & - \\
\hline 2 & $\begin{array}{l}\text { Emphasizing the importance } \\
\text { of learning in context }\end{array}$ & $\begin{array}{l}\text { Synaptic networks } \\
\text { Learning in context } \\
\text { Hebb's law }\end{array}$ & $\begin{array}{l}\text { Metacognitive } \\
\text { discussion } \\
\text { Presentation }\end{array}$ & $\begin{array}{l}\text { Synaptic network } \\
\text { presentation }\end{array}$ \\
\hline 3 & $\begin{array}{l}\text { Emphasis of the brain } \\
\text { plasticity. }\end{array}$ & Neuroplasticity & $\begin{array}{l}\text { Multi-sensory use in } \\
\text { teaching. } \\
\text { Combining movies in } \\
\text { teaching }\end{array}$ & $\begin{array}{l}\text { Plasticine } \\
\text { Youtube movies on } \\
\text { the topic of } \\
\text { Neuroplasticity } \\
\text { Quiz game }\end{array}$ \\
\hline
\end{tabular}


A general introduction to metacognition and the brain

Acquaintance with spaced learning and metacognitivecritical thinking about it the importance of evidencebased teaching between brain and reading of Mirror Neurons and learning by imitation of the concept "Working the brain by a physicalcognitive experiment to metacognition and metacognitive strategies in relation to the brain

10

Acquaintance with the concept Neuromyths of neuromyths and discussing A brief introduction to recent literature about the connection

Imaging devices

Acquaintance with the concept Expanding the understanding Memory" and its connection to Providing systematic exposure

Metacognition
Metacognitive
questions
Metacognitive
strategies and reading
strategies
Mirror Neurons
Working Memory
Physical activity and
the brain
Metacognition
Metacognitive skills
Metacognitive
knowledge
Metacognitive
strategies
Spaced learning and its
benefits according to
evidences from the
brain

Casting votes on phrases relating to the brain and confrontation about them

Critical discussion:

Ethics

Presentation
Role play
Creating a conceptual map

\section{Modeling \\ Demonstration}

Active physical

learning

An experiment

Presentation
Demonstration by
dealing with pre-
reading strategies

Experience in the classroom combined with spaced learning
Signs similar to

traffic lights for

"True" or "False"

Presentation

Memo notes

Cognitive/

Metacognitive

questions

Reading diagnostic

kit

The Jellyfish Game

The Japanese exercise

A ball

\subsection{Structure of the NMTTP Program}

The ten lessons of the NMTTP (see Table 1) refer to the original reading course and implementation of concepts and motifs from neuroscience into the lessons, at the content level and with proposed teaching methods. Almost each lesson plan was constructed with a similar outline:

- Report status: Reading Course - A short review of the status of the reading course and the specific unit currently studied;

- Important concepts from the NE field

- Recommended teaching methods which are aimed to encourage active learning and are grounded on evidencebased information from the literature;

- In practice - The lesson's steps in detail;

- Implications for teacher training: Proposed questions and discussions with the PSTs about the implications of the lesson to their work and their professional identity development;
- What else? Recommendations for more reading, connections to other lessons, etc.

The units of neuroscience in the reading class were presented at the beginning of each lesson, but, if needed, the neuroscience elements were discussed in a flexible manner throughout the whole lesson. With the exception of the preplanned lessons, the other lessons followed the original syllabus, which focuses on content regarding reading. In all the lessons, two main motifs of the NMTTP were included: learning in context and metacognition. To emphasize this point, after the concepts of learning in context, which were presented in the $2^{\text {nd }}$ lesson, each lesson began with a rehearsal on the previous lesson in different creative ways (such as: playing with a ball, fun-quiz, role play, case studies etc.) with continuous rehearsals about the importance of synaptic connections in learning concepts. Each lesson, or part of the lesson which was dedicated to understanding brain functions, was summarized through urging metacognitive discussion with the PSTs about the 
possible implementations of the new concepts in practice, critical thinking about the advantages and disadvantages of each teaching method chosen to teach the concept etc.

\subsection{Proposed Assessment of the NMTTP Implementation}

The final step in describing an intervention program or a curriculum design, according to Remesh (2017) is describing its assessment. The assessment of the NMTTP was done in several ways, such as: first, semi-structured interviews with PSTs from the classes participating in the study, describing the process of implementation as perceived by them; second, tracking and locating the motifs and methods of the NMTTP in the PSTs' lesson plans for special education pupils; third, open-ended questions tracked the concepts from the NE field and the perceived importance of NE in a mid-term and final exam of the students in the reading course. Finally, through specific questionnaires, several psychological variables can be assessed pre- and post-program, such as: changes in attitudes toward the assimilation of change in teaching methods, change in general teacher self-efficacy and teacher self-efficacy to implement motifs from NE in class.

The results regarding the implementation and assessment of this neuroscience-based program in Israeli pre-service teachers were already published in a paper by Luzzatto \& Rusu (2019), but the paper did not include the detailed description of the curriculum of the program. A number of 90 PSTs participated in the NMTTP program, which was conducted during the academic year 2017-2018. The main findings from the quantitative part indicated that the PSTs' self-efficacy regarding the use of concepts from $\mathrm{NE}$ in teaching was significantly higher among the Experimental group before the intervention and higher among the Comparison group after the intervention and the attitudes toward implementation of neuroscience in education were high in both groups before and after the intervention (Luzzatto \& Rusu, 2019). The findings from the qualitative part have not been published yet, but they also indicate general positive attitudes toward NE and the NMTTP, and show implementation of motifs from the NE field as reflected in the PSTs' lesson plans.

\section{Discussions and Conclusions}

The aim of this study was to describe a neuroscience intervention program and a suggested curriculum for implementation of motifs from neuroscience in a reading class for pre-service teachers in Special Education track. In addition, this study presented the current literature addressing NE and curriculum, described the gap in knowledge concerning it and focused on the need for constructing a neuroeducational curriculum, specifically when dealing with learning disabilities. According to Dressler et al. (2018), practical applications based on neuroscientific knowledge should be continuously evaluated throughout real-world implementation to determine their effects. To do so, more interdisciplinary collaboration between neuroscience and real-world education is needed, which may result in new concepts and messages that are both supported by science and are educationally informative (Howard-Jones, 2014). Nevertheless, NE programs, especially those which include implementation are relatively scarce in already existing courses (Murphy, 2017).

For educators in general, and PSTs specifically, a NE program or NE-implementation based curriculum would be beneficial on several personal and professional dimensions. This study introduces a neuroscience intervention program in an existing reading course for special education PSTs. The intervention program, in part, is reflected in a change in the curriculum. The included neuroscience concepts were considered in relation to learning disabilities, especially dyslexia, which was the focus of the course. However, the intervention program's main concepts were also aimed to encourage a general change so that teaching will become evidence-based, as well as a change in teaching methods and the way PSTs relate to their methods of teaching including the rationale of their choices.

According to García Carrasco et al. (2015), neurosciences can bring to education much more than the understanding of the brain and more than answers to problem situations. The neuro-educational argument may extend the understanding of learning and education in general. Reviewing the current literature dealing with $\mathrm{NE}$ reveals that, although many of the studies emphasize the importance of $\mathrm{NE}$ as an innovative teaching content and method (e.g Ansari et al., 2012; Murphy, 2017), only few studies describe implementation of NE in practice. Within these programs, particular features of the NMTTP can be found, as detailed below:

\section{a. Implementation in an Existing Syllabus}

Among the few curricula or syllabuses discussing NE, it seems that the prominent ones are studied separately from other courses, and not from an interdisciplinary or integrative point of view. For example, Warner \& Tempelson (2010) suggest a course-embedded guided inquiry project for 20 elementary education teacher candidates enrolled in a course called "Learning and the Brain". This course was aimed for brain-targeted math games and activities. During the formulation stage, the participants suggested creative ideas for curriculum development and together with a teacher in residence they collected lesson plans consistent with their developing ideas and insights about the neuroeducational paradigm. In 2007, 
Blake \& Gardner described "The First Class in Mind, Brain and Education" which dealt with the connection between biological, psychological and educational aspects of learning while using innovative teaching methods. According to the authors, the course trained students to evaluate research findings and engage in new forms of integrative thinking. One of the final requisites of the course was a project that entailed empirical research, curriculum design, or a theoretically oriented essay. Yet, this course was taught separately from other courses. Another example mentioned above is the Neuropedagogy Adaptation Project (NAP) as presented in Friedman et al. (2019) research. While the NAP's participants studied an elective course, which connected neuroscience and education from a general perspective, the NMTTP'S participants took an obligatory course and the concepts from the neuroscience field were implemented with concepts from the reading field, with constant relation to the reading lesson planning for pupils. Rooks and Winkler (2012) discussed the advantages of multidimensional interdisciplinarity courses: (1) students learn that knowledge is not compartmentalized and that in the real world, knowledge is transferable and cumulative; (2) interdisciplinarity courses allows students to understand how to marshal a wide range of skills and knowledge bases to solve pressing social, economic, and technological problems; (3) it encourages different ways of learning, specifically more collaborative approaches that promote dialogue and problem-solving capacities.

Curtis and Fallin (2014) suggested implementation of $\mathrm{NE}$ concepts into music lessons. According to the authors, collaboration between the different fields must occur in two levels, in both content and capacity. One of their suggestions for such collaboration is through curriculum, which can help students understand more clearly the connections between what is taught and why it is of value for them to know and understand. In spite of this suggestion, it remained in the theoretical perspective, while the NMTTP took this idea and transferred it into a practical level. Unlike other programs, such NAP or BrainU, which focus on teaching students neuroscience or NE in a separate course or program, the NMTTP intervention program insisted on implementation of motifs from the neuroscience field in an existing reading course, from a point of view that the best transfer and implementation will occur when content is part of a current lesson. Therefore, the principles of the NMTTP can be adjusted to almost any other course, with accommodations.

\section{b. NMTTP Chosen Topics and Concepts}

Although the topics for the NMTTP were based on the guidelines of the Brain Targeted Teaching Model (BTT) by Hardiman (2012), and the ideas of Tokuhama- Espinosa (2011), it also included other motifs and emphasized specific topics and concepts which were relevant to the reading class in the special education track. Also, although some of the topics in the NMTTP were similar to the NAP (Friedman et al, 2019), the NMTTP also dealt with other aspects that weren't mentioned in the NAP, such as metacognition, mirror neurons, spaced learning and more. The NMTTP was reflected in an original, special implemented module in the curriculum of the reading course, and the principles of it can be integrated in many other courses as well.

c. Implementation in a Teacher Training Program

The few programs dealing with implementation of NE are directed to in- service teachers. According to Dubinsky et al. (2019), their project, BrainU, serves as a model program for teaching neuroscience to both preservice and in-service teacher audiences. However, the fact is that this project was tested only for in- service teachers. Moreover, the Neuropedagogy Adaptation Project (NAP), as proposed in the Friedman et al. (2019), links the knowledge regarding the function of the brain and educational processes, similarly as some of the topics in the NMTTP. However, this program was also aimed to in-service teachers and educational staff who already work in schools, and they participated in the NAP as part of their master degree. The NMTTP, however, is aimed to PSTs in their first degree, based on the idea that implementation of NE during the training period might have a beneficial effect as their professional identity develops in this stage. PSTs who practice NE might, hopefully, implement it into their lesson planning, and thinking and teaching methods more easily than in- service teachers who already have specific habits of teaching.

\section{d. Implementation of a Program for Special Education Teachers}

Although different researchers talked about the importance of NE to achieve a better understanding of special education in general and learning disabilities in particular (Hardiman, 2012a; Kosaraju et al 2014; Stern, et al, 2016), few studies have made the connection between these fields in practice. The different intervention programs reviewed in this study weren't targetted for special education teachers. However, the NMTTP took place in a special education track course, and was aimed to consider the different needs of pupils with reading difficulties regarding concepts and methods from the neuroscience field. Since children with learning disabilities have difficulties in embracing learning strategies on their own, there is a possible contribution of a program focusing on evidence- based methods to improve teaching and learning in this population.

e. Consideration of the assessment of PSTs selfefficacy and attitudes toward change 
Although this point is not a direct characteristic of the NMTTP, examining its impact on PSTs self-efficacy to implement motifs from NE in their teaching and examining the program's impact on their attitudes toward change and implementation of neuroscience motifs is a way of assessing the NMTTP impact.

In terms of identified limitations, it is important to mention that the NMPPT was design as an original training program for Israeli PSTs in the field of special education. One of the characteristics of the program was that it was implemented in an existing reading course, due to the advantages of interdisciplinary learning (Rooks, \& Winkler, 2012). Since the syllabus of the reading course already existed as a whole, it was sometimes difficult to implement the motifs from the neuroscience/NE field, since there was pressure to teach the original material of the course. Future studies may better formulate the correct form for embedding NE content into an existing course. Although the results of the implementation of the program are not presented here, data indicate promising results regarding the influence of NE training program on PST's self-efficacy and the opening of the Israeli PSTs towards implementation of motives from neuroscience in education.

Authors note: No potential conflict of interest was reported by the authors. The authors had equal contributions to this article.

Efrat Luzzatto is a pedagogical instructor and a lecturer in the special education track in one of the main teacher training institutes in Israel. Since 2016, she is a PhD student at Babes-Bolyai University, Cluj-Napoca, Romania. Her research areas are aimed to develop and explore an intervention program (NMTTP) that implement motifs from neuroscience in a reading course. She teaches courses in learning disabilities, reading accommodations for students with special needs and constructing intervention programs for students with learning disabilities.

Alina S. Rusu (biologist and psychologist) is currently an Associate Professor in the Department of Special Education, Faculty of Psychology and Educational Sciences, Babes-Bolyai University, Cluj-Napoca, Romania and member of the Doctoral School "Education, Reflection, Development" (domain: Sciences of Education). Her research interests are: humane education, interdisciplinary curriculum development, applied values of human-animal interactions and the multidimensional study of communityoriented volunteering. She teaches courses in animal psychology, psychobiology of human sexuality, and positive psychology applied to inclusive institutions.

\section{References}

Ansari, D., De Smedt, B., \& Grabner, R.H. (2012). Neuroeducation - a critical overview of an emerging field. Neuroethics, 5(2), 105-117.

Baddeley, A. (1992). Working memory. Science, 255(5044), 556-559.

Boets, B., de Beeck, H.P.O., Vandermosten, M., Scott, S.K., Gillebert, C.R., Mantini, D., ... \& Ghesquière, P. (2013). Intact but less accessible phonetic representations in adults with dyslexia. Science, 342(6163), 1251-1254.

Bergman, E.M., de Bruin, A.B., Vorstenbosch, M.A., Kooloos, J.G., Puts, G.C., Leppink, J., ... \& van der Vleuten, C.P. (2015). Effects of learning content in context on knowledge acquisition and recall: a pretestposttest control group design. BMC Medical Education, 15(133), 1 -11.

Blake, P.R., \& Gardner, H. (2007). A first course in mind, brain, and education. Mind, Brain, and Education, 1 (2), 61-65.

Bravo, L. (2014). Neuroscience and education: current state of research on dyslexia/Neurociencias y educación: estado actual de la investigación en dislexias. Estudios de Psicología, 35 (1), 1-28.

Clement, N.D., \& Lovat, T. (2012). Neuroscience and education: Issues and challenges for curriculum. Curriculum Inquiry, 42(4), 534-557.

Curtis, L., \& Fallin, J. (2014). Neuroeducation and music: Collaboration for student success. Music Educators Journal, 101(2), 52-56.

Devonshire, I.M., \& Dommett, E.J. (2010). Neuroscience: Viable application in education? Neuroscience and Society, 16, 349-356.

Dresler, T., Bugden, S., Gouet, C., Lallier, M., Oliveira, D.G., Pinheiro-Chagas, P., \& Weissheimer, J. (2018). A Translational Framework of Educational Neuroscience in Learning Disorders. Frontiers in Integrative Neuroscience, 12, 1-12.

Dubinsky, J.M., Roehrig, G., \& Varma, S. (2013). Infusing neuroscience into teacher professional development. Educational Researcher, 42(6), 317-329.

Dubinsky, J.M., Guzey, S.S., Schwartz, M.S., Roehrig, G., MacNabb, C., Schmied, A., \& Ellingson, C. (2019). Contributions of Neuroscience Knowledge to Teachers and Their Practice. The Neuroscientist, 5(5), 394-407.

Ergas, O., Hadar, L.L., Albelda, N., \& Levit-Binnun, N. (2018). Contemplative neuroscience as a gateway to mindfulness: Findings from an educationally framed teacher learning program. Mindfulness, 9(6), 17231735 .

Friedman, I. A., Grobgeld, E., \& Teichman-Weinberg, A. (2019). Imbuing education with brain research can 
Improve teaching and enhance productive learning. Psychology, 10(02), $122-131$.

Gabrieli, J.D. (2016). The promise of educational neuroscience: Comment on Bowers (2016). Psychol. Rev., 123, 613-619. doi:10. 1037/rev0000034.

García Carrasco, J., Hernández Serrano, M.J., \& Martín García, A.V. (2015). Plasticity as a framing concept enabling transdisciplinary understanding and research in neuroscience and education. Learning, Media and Technology, 40(2), 152-167.

Goswami, U. (2008). Cognitive development- The learning brain. Psychology Press: University of Cambridge.

Hardiman, M. (2012a). Informing pedagogy through the brain-targeted teaching model. Journal of Microbiology \& Biology Education: JMBE, 13(1), 1116.

Hardiman, M. (2012b). The brain-targeted teaching model for 21st-century schools. Corwin Press.

Howard-Jones, P.A. (2014). Neuroscience and education: myths and messages. Nature Reviews Neuroscience, 15(12), 817-824.

Hoffenbartal, D. (2014). The development of a sense of coherence in teaching situations among special education pre-service teachers. [Doctoral Dissertation, Babes-Bolyai University, Romania].

Katzir, T., \& Pare-Blagoev, J. (2006). Applying cognitive neuroscience research to education: The case of literacy. Educational Psychologist, 41 (1), 53-74.

Kearns, D.M., Hancock, R., Hoeft, F., Pugh, K.R., \& Frost, S.J. (2019). The neurobiology of dyslexia. Teaching Exceptional Children, 51 (3), 175-188.

Keysers, C., Kohler, E., Umiltà, M.A., Nanetti, L., Fogassi, L., \& Gallese, V. (2003). Audiovisual mirror neurons and action recognition. Experimental Brain Research, 153(4), 628-636.

Kosaraju, S., Gorman, M.A., \& Berry, K. (2014). Conceptualizing the NET: The Neuroeducation Translational (NET) research model-A framework for neuroscience research to special education practice. Journal of Interdisciplinary Studies in Education, 2(2), 38-49.

Moss, J., Schunn, C.D., Schneider, W., \& McNamara, D.S. (2013). The nature of mind wandering during reading varies with the cognitive control demands of the reading strategy. Brain Research, 1539, 48-60.

Murphy, S.C. (2017). The promise and pitfalls of neuroeducation as a grounding for instructional practices: An exploration of K-12 application and assessment. Graduate Theses and Dissertations. Retrieved from: https://pilotscholars.up.edu/etd/19.

Nouri, A. (2013). Practical strategies for enhancing interdisciplinary collaboration in neuroeducational studies. International Journal of Cognitive Research in Science, Engineering and Education (IJCRSEE), 1(2), 94-100.

Partanen, M.H. (2017). Academic and neuroimaging outcomes of school-based reading interventions (Doctoral dissertation, University of British Columbia).

Ram-Tsur, R., \& Litmanovitch, I. (2018). Short breaks during the lesson. The Initiative for Applied Education Research. Retrieved from http://education.academy.ac.il/SystemFiles/23252.pdf (Hebrew).

Remesh, A. (2017). Curriculum design principles for developing a module in medical education. Progress in Medical Sciences, 1(1), 34-37.

Rooks, D., \& Winkler, C. (2012). Learning interdisciplinarity: Service learning and the promise of interdisciplinary teaching. Teaching Sociology, 40(1), 2-20.

Rueda, C. (2020). Neuroeducation: Teaching with the brain. Journal of Neuroeducation, 1(1), 108-113.

Sousa, D.A. (2010). Mind, brain, \& education: Neuroscience implications for the classroom. Solution Tree Press.

Smolen, P., Zhang, Y., \& Byrne, J.H. (2016). The right time to learn: Mechanisms and optimization of spaced learning. Nature Reviews Neuroscience, 17 (2), 77-88.

Stern, E., Grabner, R.H., \& Schumacher, R. (2016). Educational neuroscience: A field between false hopes and realistic expectations. Zeitschrift für Psychologie, 224, 237-239.

Tokuhama-Espinosa, T. (2011). Mind, brain, and education science: A comprehensive guide to the new brain-based teaching. WW Norton \& Company.

Tokuhama-Espinosa, T. (2017). International Delphi panel on Mind Brain, and Education science. Quito, Ecuador. DOI: 10.13140/RG.2.2.14259.22560.

Tokuhama-Espinosa, T. (2018). Using Research from the Learning Sciences to Improve Teaching. New York: The American Educational Research Association.

Warner, S., \& Templeton, L. (2010). Embedded librarianship and teacher education: a neuroeducational paradigm using guided inquiry. Public Services Quarterly, 6(2-3), 250-258.

Young, A., \& Fry, J.D. (2008) Metacognitive awareness and academic achievement in college students. Journal of the Scholarship of Teaching and Learning, 8 (2),110.

***Achva Model of neuropadagogy (2016), retrieved from: http://www.achva.ac.il/ (Hebrew)

***OECD Report (2007). Retrieved from https://www.oecd.org/newsroom/38528123.pdf. 